\title{
Perceived Risk of Mental Health Problems in Primary Care
}

\author{
Constança Paúl1*, Laetitia Teixeira', Maria João Azevedo', Sara Alves', \\ Mafalda Duarte', Rónán O'Caoimh ${ }^{2,3,4}$ and William Molloy',3 \\ ${ }^{1}$ Research and Education Unit on Ageing, Institute of Biomedical Sciences Abel Salazar, University of Porto, Porto, Portugal, \\ ${ }^{2}$ Centre for Gerontology and Rehabilitation, St Finbarrs Hospital - University College Cork, Cork City, Ireland, \\ ${ }^{3}$ COLLaboration on AGEing, University College Cork, Cork, and NetwellCASALA - Dundalk Institute of Technology, Dundalk, \\ Ireland, ${ }^{4}$ Health Research Board, Clinical Research Facility Galway, National University of Ireland, Galway, Ireland
}

\section{OPEN ACCESS}

Edited by:

Atsushi Takeda, National Hospital Organization Sendai-Nishitaga Hospital, Japan

Reviewed by: Kenji Wada,

Tottori University, Japan Kouichi Ohta,

Tachikawa Hospital, Japan

${ }^{*}$ Correspondence: Constança Paúl paul@icbas.up.pt

Received: 07 April 2015 Accepted: 28 October 2015 Published: 17 November 2015

Citation:

Paúl C, Teixeira L, Azevedo MJ, Alves S, Duarte M, O'Caoimh R and Molloy W (2015) Perceived Risk of Mental Health Problems in Primary Care. Front. Aging Neurosci. 7:212. doi: 10.3389/fnagi.2015.00212
In the face of limited resources and an aging population with increasingly care needs, healthcare systems must identify community-dwelling older adults with mental health problems at higher risk of adverse outcomes such as institutionalization, hospitalization and death, in order to deliver timely and efficient care. The objectives of this study were to assess the prevalence of mental health concerns and the associated perceived risk of adverse outcomes in a large sample of older patients in primary care (PC). We trained general practitioners and nurses to use the Risk Instrument for Screening in the Community to rank perceived risk of mental health concerns (including neurocognitive and mood disorders) from 1 (mild) to 3 (severe). The mean age of the 4499 people assessed was 76.3 years $(S D=7.3)$ and $2645(58.8 \%)$ were female. According to the PC team 1616 (35.9\%) were perceived to have mental health concerns of whom 847 (52.4\%) were mild, 559 (34.6\%) were moderate and 210 (13\%) were severe. Patients with mental health concerns had higher odds of perceived risk of adverse outcomes $(\mathrm{OR}=2.22,95 \% \mathrm{Cl} 1.83-2.69$ for institutionalization; $\mathrm{OR}=1.66,95 \% \mathrm{Cl} 1.41-1.94$ for hospitalization; $\mathrm{OR}=1.69,95 \% \mathrm{Cl} 1.42-2.01$ for death). These results suggest a high prevalence of mental health concerns among older adults and supports the need for early identification of patients at high-risk of adverse healthcare outcomes.

Keywords: risk, primary care, old people, mental health, RISC

\section{INTRODUCTION}

There is growing recognition of the need to develop inclusive health service policies to integrate and track mental health issues. Previously surrounded by misconceptions and stigma, the importance of good mental health is now widely accepted. Reasons to promote the integration of mental health issues into primary care (PC) include: "(1) The burden of mental disorders is great; (2) Mental and physical health problems are interwoven; (3) The treatment gap for mental disorders is enormous; (4) PC for mental health enhances access; (5) PC for mental health promotes respect of human rights; (6) PC for mental health is affordable and cost-effective; (7) PC for mental health generates good health outcomes" (WHO and WONCA, 2008). More recently, the World Health Assembly recognized the extent to which mental and neurological disorders including Alzheimer's disease can cause morbidity and subsequent disability (WHA, 2012).

Mental health disorders including neurocognitive disorders affect approximately 165 million (38.2\%) people in the European Union (EU), with no substantial cultural or country variations 
for most conditions (Wittchen et al., 2011). Mental health disorders contribute to $26.6 \%$ of the total burden of disease [disability adjusted life years (DALY)] in Europe (Wittchen et al., 2011). Recognizing the differences between study methods, the lifetime prevalence of mental health problems may still be as high as 57\%, particularly in lower socioeconomic groups (Rabins et al., 1996). Excluding dementia, the prevalence of psychiatric disorders is estimated at $16.3 \%$, potentially rising to $21.6 \%$ by the year 2030 (Jeste et al., 1998). Psychiatric disorders are underestimated because of cognitive impairment, physical disorders, ageism or because older people attribute feeling depressed to old age itself and are discouraged from seeking help or reporting symptoms (Sarkisian et al., 2003). Others have subclinical disorders that do not meet the diagnostic criteria for psychiatric disorders but require attention (Xavier et al., 2013), contributing significantly to morbidity and mortality (Gallo et al., 1997; Steffens et al., 2000). The prevalence of these disorders approaches 33\% in people 70 years and over (the Berlin Aging Study) (Helmchen et al., 1999). In Portugal, the annual prevalence of mental disorders is $22.9 \%$, with $7.3 \%$ reported as mild, $11.6 \%$ as moderate and $4 \%$ as severe (Caldas de Almeida and Xavier, 2013). The Portuguese National Inquiry on Health (INE, 2009) showed that there is a high prevalence of probable psychological distress in older people that varies from $40.6 \%$ in people aged $65-74$ years to $42.2 \%$ in those aged $75-$ 84 years, reducing to $36.3 \%$ by 85 years. The percentage of women with psychological suffering is higher than for man, affecting half of older Portuguese women. These data are in line with international comparative studies that show that Portugal ranks high compared to other nations (Caldas de Almeida and Xavier, 2013).

Mental and physical health problems are often interwoven, particularly in older people (WHO and WFMH, 2010). The bidirectional negative impact of physical disease and depression may result in further disability (Menchetti et al., 2001) and is independently associated with an increased risk of mortality (Ganguli et al., 2002).

In high-income countries between 35 and $50 \%$ of people receive insufficient treatment (WHA, 2012), often due to underdetection and/or inadequate access resulting in a large treatment gap for mental disorders. Utilizing PC resources is crucial to overcome this, particularly in Portugal where $17 \%$ of patients with mental health problems seek help in PC compared to $11 \%$ in other EU countries (EC, 2010). Training health professionals to recognize mental health concerns by providing them with efficient and effective instruments is a first step to insure that older people can get proper treatment for their condition (WHA, 2012). Four theoretical models of managing mental health disorders in PC include: training; consultation-liaison; collaborative care, and replacement/referral (Bower and Gilbody, 2005). The training of PC professionals to identify and manage risk factors seems most appropriate.

Another important component is to support patients with mental health disorders in their home environment by supporting their caregivers or social network. Caregivers (mainly family) are considered the backbone of long-term care systems (OECD, 2013). The positive effect of an informal carer is well-recognized in mental health, particularly where the caregiver assumes the role of confident. On the other hand, caregiver strain or burden increases the risk of adverse healthcare outcomes (Paúl and Martin, 2003; Carretero et al., 2009). The number of people aged 50 or more years reporting to be caregivers in 2010 was $15.6 \%$ with $62.3 \%$ being women and $87 \%$ providing care on a daily basis (OECD, 2013). In Portugal, as in most of the southern European countries, there is a strong culture of family providing care for their older relatives, mainly supported by women (Lopes, 2013).

Given the importance of integrating mental health services into PC by efficiently and effectively screening and triaging patients with mental health disorders, this paper aims to: (i) establish the point prevalence of mental health concerns among community-dwelling older adults in PC in northern Portugal, (ii) identify predictive factors associated with mental health concerns, and (iii) determine the extent that mental health concerns affect patients perceived risk of three adverse healthcare outcomes: institutionalization, hospitalization and death as perceived by healthcare professionals working in the community using a new, short, global subjective risk prediction instrument called the Risk Instrument for Screening in the Community (RISC; O'Caoimh et al., 2014, 2015c).

\section{MATERIALS AND METHODS}

\section{Study Design}

This paper presents cross sectional data from a large, on going, prospective cohort study on mental health in northern Portugal. The project was approved by the ethics committee of the Regional Association of Health North (ARS North) and by each of the 24 Associations of Health Centers in the region where data was collected.

\section{Participants}

The sample comprises 4499 consecutive patients attending 29 PC practices who met the following inclusion criteria: (i) aged $>=65$ years-old; (ii) living in the community; (iii) PC patients; (iv) living in the area covered by the ARS North; (v) provided informed consent. The exclusion criteria included patients aged less than 65 years, those deemed to be actively dying, including those receiving palliative care, and those already in institutional care, i.e., nursing home residents. Those not attending the PC center regularly, i.e., those lost to regular followup/attendance were also excluded as no accurate demographic data were available and they could not be scored with the RISC.

\section{Measures}

The RISC is a short (2-5 min), reliable (O'Caoimh et al., 2012, 2014) and valid global subjective assessment of risk. It has good internal consistency (O'Caoimh et al., 2015b,c). It is used as a pre-screen stratifying patients according to their risk level and is scored with a five point Likert scale from 1 to 5 , where 1 is the lowest risk and 5 is the highest of three adverse health care outcomes (institutionalization, hospitalization, and 
death) at 1 year from assessment. Each outcome is scored separately. The RISC also collects demographic data and scores the ability of the caregiver network (both formal and informal) to manage risk across three domains: the patients' Mental State, ADL State and Medical State, which can be used to inform the subjective assessment. The caregiver network score is again presented as a five point Likert scale, scored from 1 (can manage all risks) to 5 (the caregiver network is a liability or is absent). Risk is determined by a subjective assessment based upon the information gathered such that: risk equates to the severity of the concern minus the protective effect of the caregiver network for each of the three domains. The RISC is available at http://www.biomedcentral.com/1471-2318/14/104/ figure/F1. Patients can be grouped into minimum (RISC scores 1 and 2) and maximum-risk (RISC scores 3-5) to facilitate analysis.

The RISC was developed in University College Cork (UCC), Ireland, as part the Community Assessment of Risk Treatment and Strategies (CARTS) program, a component of Irelands successful three star reference site application under the European Innovation Partnership on Active and Healthy Ageing (Sweeney et al., 2013; O'Caoimh et al., 2015d). The RISC was initially validated in Ireland against the Clinical Frailty Scale (CFS; Rockwood et al., 2005), an established frailty instrument, in 803 community dwelling older adults, aged over 65 years (O'Caoimh et al., 2014, 2015c; LeahyWarren et al., 2015). Public health nurses scored the RISC and CFS for each patient and independent investigators, blind to the RISC score, followed up individual outcomes at 1 year. Those classified as maximum-risk were significantly more likely to experience all three outcomes (institutionalization, hospitalization, and death) at 1 year. The RISC had greater accuracy compared with the CFS, albeit it was a non-significant difference. The RISC better predicted institutionalization and death than hospitalization. A recent systematic review of riskprediction instruments in the community confirmed that the risk compares favorably with similar tools, all of which have poor accuracy in predicting hospitalization (O'Caoimh et al., 2015a).

\section{Procedures}

The RISC was firstly translated from English into Portuguese by a committee of three experts in gerontology, all fluent in English. The Portuguese version of the RISC was then back translated into English. To ensure semantic equivalence and acceptability, this process was performed by a professional English translator and by a professional with experience in gerontology. The draft version was discussed with the team of authors and some minor changes were made. The instrument was piloted by a group of five healthcare professionals to ensure comprehensibility and no further changes were introduced.

Healthcare professionals, general practitioners (GPs) and practice nurses who agreed to participate, received $4 \mathrm{~h}$ of training and certification in scoring the RISC, delivered by the Portuguese research team that had itself received a 2-day training session from the authors of the RISC in UCC, Ireland. RISC training introduces the concept of risk and adverse outcomes; it discusses the main areas of concern (mental, functional, and medical), its relevance for the assessment, its contents and scoring instructions. RISC training is shown to increase interrater reliability (O'Caoimh et al., 2012). Once trained, GPs and a small number of practice nurses scored the RISC on their own patients only, using their clinical knowledge of each patient's current health status.

\section{Statistical Analysis}

Descriptive statistics were used to characterize the sample. Potential predictive factors relating to mental health concerns were tested using univariable logistic regression models. Considering covariates statistically significant in univariable models, a multivariable logistic regression model was performed.

Additionally, the effect of the presence/absence of mental health concerns, the severity and the ability of the caregiver network were tested as potential predictive factors of the risk of each adverse outcome (institutionalization, hospitalization, and death) in three distinct multivariable logistic regression models (adjusting for age, gender, ADL and medical concerns). The Akaike information criterion (AIC) were obtained to compare non-nested logistic models. In order to evaluate the discriminant capacity of each model, the area under the curve (AUC) obtained from receiver operator characteristic (ROC) curves was used. Comparisons of ROC curves for the same adverse outcome

TABLE 1 | Characteristics of the sample.

\begin{tabular}{|c|c|c|}
\hline & $n$ & $\%$ \\
\hline \multicolumn{3}{|l|}{ Gender } \\
\hline Male & 1854 & 41.2 \\
\hline Female & 2645 & 58.8 \\
\hline Age in years [mean(SD)] & $76.3(7.3)$ & \\
\hline \multicolumn{3}{|l|}{ Living alone } \\
\hline Yes & 734 & 16.7 \\
\hline No & 3653 & 83.3 \\
\hline \multicolumn{3}{|l|}{ Mental health concerns } \\
\hline No & 2883 & 64.1 \\
\hline Yes & 1616 & 35.9 \\
\hline \multicolumn{3}{|l|}{ Severity } \\
\hline Mild & 847 & 52.4 \\
\hline Moderate & 559 & 34.6 \\
\hline Severe & 210 & 13.0 \\
\hline \multicolumn{3}{|c|}{ Caregivers ability to manage mental health concerns } \\
\hline Can manage & 783 & 48.5 \\
\hline Carer strain & 531 & 32.9 \\
\hline Some gaps & 221 & 13.7 \\
\hline Cannot manage & 81 & 5.0 \\
\hline Absent/liability & 0 & 0.0 \\
\hline \multicolumn{3}{|l|}{ ADLs concerns } \\
\hline No & 2456 & 54.6 \\
\hline Yes & 2043 & 45.4 \\
\hline \multicolumn{3}{|l|}{ Medical concerns } \\
\hline No & 977 & 21.7 \\
\hline Yes & 3222 & 78.3 \\
\hline
\end{tabular}


were performed considering a proposed approach (Hanley and McNeil, 1983). The significance level was set at 0.05 for all analysis.

\section{RESULTS}

The sample comprises 4499 patients with a mean age of 76.3, standard deviation (SD) of 7.3 years, range $65-103$ years. Of these 1854 (41.2\%) were male and 2645 (58.8\%) female. Only 734 patients $(16.7 \%)$ were living alone. In total, $1616(35.9 \%)$ of the patients were scored as having mental health concerns using the RISC, 2043 (45.4\%) with ADL concerns and 3222 (78.3\%) with medical concerns. Of patients registering mental health concerns on the RISC, less than half (48.5\%) had a caregiver network that was perceived to be able to manage the situation. Option five of the care network (absence/liability) was not considered in the analysis because of the absence of records (Table 1). Evaluating the risk of adverse outcomes showed that $16.3 \%$ of the sample were perceived to be at risk of institutionalization, $32.8 \%$ at risk of hospitalization and $23.1 \%$ at risk of death.

\section{Predictive Factors of Mental Health Concerns}

In order to identify potential predictive factors of mental health concerns, univariable logistic regression models were performed. Results are shown in Table 2. Females had greater odds of mental health concerns [odds ratio $(\mathrm{OR})=1.26,95 \%$ confidence interval (CI) 1.11-1.43] compared with males. Patients with either ADL concerns (OR = 10.1, 95\% CI 8.76-11.7) or medical concerns $(\mathrm{OR}=6.01,95 \% \mathrm{CI} 4.88-7.44)$ also had greater odds of having mental health concerns. Increasing age increased the risk of having mental health concerns (OR $=1.08,95 \%$ CI 1.071.09) while living arrangement was not related to mental health concerns.

Considering significant factors of mental health concerns obtained in univariable models, a multivariable logistic regression model was performed and all factors remained statistically significant with the exception of gender. This reinforces that the presence of ADL and medical concerns and older age were associated with higher odds of mental health concerns (Table 2).

\section{Mental Health as a Predictive Factor of Adverse Healthcare Outcomes}

Three multivariable logistic regression models were performed for the risk of each adverse outcome (institutionalization, hospitalization, and death). Model 1 (M1) included the presence/absence of mental health concerns, model 2 (M2) included the severity of concerns and model 3 (M3) the ability of the caregiver network to manage risk. Gender, age, ADLs, and medical concerns were included as covariates. Results are presented in Table 3.

All three predictive factors (living alone, ADL concerns, and Medical concerns) of the three adverse healthcare outcomes were statistically significant. Patients with mental health concerns had greater odds of perceived risk of each adverse outcome $(\mathrm{OR}=2.22,95 \%$ CI $1.83-2.69$ for risk of institutionalization; $\mathrm{OR}=1.66,95 \%$ CI $1.41-1.94$ for risk of hospitalization; $\mathrm{OR}=1.69,95 \%$ CI $1.42-2.01$ for risk of death). Additionally, as the severity of concern increased, the odds of perceived risk also increased (OR for each level of severity - mild, moderate and severe - varies between 1.11 and 5.41), compared to those without mental health concerns. Finally, the odds of perceived risk of each adverse outcome increased as the ability of the caregiver network to manage mental health concern decreased (from 'can manage,' to 'carer strain,' 'some gaps', to 'cannot manage'): OR for each level of caregiver network varies between 1.07 and 16.9. Model 3 revealed a lower AIC for the risk of institutionalization, while model 2 showed a lower AIC for risk of hospitalization and death.

The results of ROC curve analysis are presented in Table 4. All models present an AUC greater than 0.80 (values varies between 0.810 and 0.838 ), suggesting good discriminatory capacity. Comparing the models for each outcome, only M1

TABLE 2 | Univariable and multivariable logistic regression models of mental health concerns.

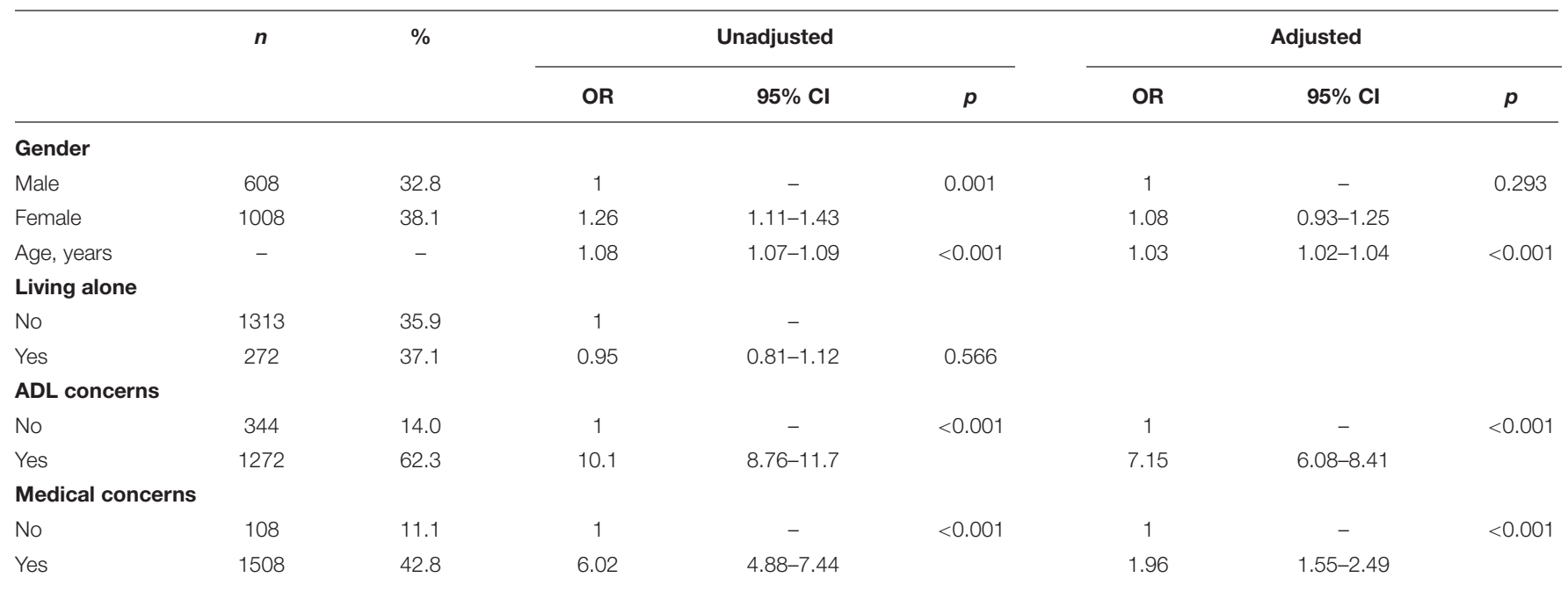


TABLE 3 | Multivariable logistic regression models of risk of adverse healthcare outcomes.

\begin{tabular}{|c|c|c|c|c|c|c|c|c|c|c|}
\hline \multirow[t]{2}{*}{ Model } & \multirow[t]{2}{*}{ Mental health } & \multicolumn{3}{|c|}{ Risk of institutionalization } & \multicolumn{3}{|c|}{ Risk of hospitalization } & \multicolumn{3}{|c|}{ Risk of death } \\
\hline & & OR & $95 \% \mathrm{Cl}$ & AIC & OR & $95 \% \mathrm{Cl}$ & AIC & OR & $95 \% \mathrm{Cl}$ & AIC \\
\hline \multirow[t]{3}{*}{ M1 } & Concerns & & & & & & & & & \\
\hline & No & 1 & - & 3197.7 & 1 & - & 4319.5 & 1 & - & 3761.3 \\
\hline & Yes & 2.22 & $1.83-2.69$ & & 1.66 & $1.41-1.94$ & & 1.69 & $1.42-2.01$ & \\
\hline \multirow[t]{5}{*}{ M2 } & Severity & & & & & & & & & \\
\hline & No & 1 & - & 3127.5 & 1 & - & 4260.9 & 1 & - & 3673.6 \\
\hline & Mild & 1.42 & $1.13-1.80$ & & 1.17 & $0.97-1.41$ & & 1.11 & $0.90-1.36$ & \\
\hline & Moderate & 2.81 & $2.21-3.57$ & & 2.28 & $1.83-2.84$ & & 2.09 & $1.66-2.62$ & \\
\hline & Severe & 5.30 & $3.82-7.36$ & & 3.85 & $2.66-5.57$ & & 5.41 & $3.79-7.72$ & \\
\hline \multirow[t]{6}{*}{ M3 } & Caregiver & & & & & & & & & \\
\hline & No & 1 & - & 2984.8 & 1 & - & 4262.8 & 1 & - & 3697.1 \\
\hline & Can manage & 1.07 & $0.84-1.38$ & & 1.26 & $1.04-1.52$ & & 1.25 & $1.01-1.55$ & \\
\hline & Carer strain & 2.11 & $1.65-2.71$ & & 1.65 & $1.32-2.06$ & & 1.80 & $1.43-2.28$ & \\
\hline & Some gaps & 8.25 & $5.93-11.5$ & & 3.35 & $2.39-4.69$ & & 2.15 & $1.57-2.95$ & \\
\hline & Cannot manage & 16.9 & $9.48-30.2$ & & 6.44 & $3.41-12.2$ & & 10.3 & $5.66-18.7$ & \\
\hline
\end{tabular}

*Models adjusted for gender, age, ADL, and medical concerns.

TABLE 4 | Discriminatory capacity of all three model to predict risk of adverse healthcare outcomes (AUC and standard error).

\begin{tabular}{|c|c|c|c|c|c|c|}
\hline \multirow[t]{2}{*}{ Model } & \multicolumn{2}{|c|}{ Risk of institutionalization } & \multicolumn{2}{|c|}{ Risk of hospitalization } & \multicolumn{2}{|c|}{ Risk of death } \\
\hline & AUC (SE) & $p^{*}$ & AUC (SE) & $p^{*}$ & AUC (SE) & $p^{*}$ \\
\hline M1 & $0.810(0.007)$ & 0.116 & $0.816(0.006)$ & 0.234 & $0.819(0.007)$ & 0.080 \\
\hline M2 & $0.824(0.007)$ & 0.005 & $0.823(0.006)$ & 0.405 & $0.828(0.007)$ & $0.050^{\prime}$ \\
\hline M3 & $0.838(0.007)$ & $0.084 "$ & $0.821(0.006)$ & 0.999" & $0.826(0.007)$ & $0.697 "$ \\
\hline
\end{tabular}

*p: comparing $\mathrm{M} 1$ and M2; p': comparing M1 and M3; p": comparing M2 and M3.

was statistically different from the M3 considering perceived risk of institutionalization as outcome $(\mathrm{AUC}=0.810$ for $\mathrm{M} 1$ and $\mathrm{AUC}=0.838$ for $\mathrm{M} 3, p=0.005)$.

\section{DISCUSSION}

This study presents the prevalence of cases of mental health concerns (composite neurocognitive and mood disorders) in the selected study population, their severity, and the perceived ability of caregiver networks to manage and the perceived risk of adverse healthcare outcomes in a large sample of community-dwelling older adults in Portugal, scored by community healthcare professional using a new short, global risk assessment instrument, akin to a brief targeted geriatric assessment, called the RISC. The results show that $35.9 \%$ of older patients presenting to PC in northern Portugal are judged by their healthcare professional to have mental health concerns. The severity of these mental health concerns was generally mild (52.4\%) although $34.6 \%$ were moderate and $13 \%$ severe. It is possible that those with mild mental health concerns do not fulfill the criteria to be diagnosed with mental health disorders but instead represent patients with subclinical mental health problems that nevertheless contribute to morbidity and mortality particularly in older people (Steffens et al., 2000; Xavier et al., 2013). The percentage of people aged 65 or more years with mental health problems, identified by the GPs in this study, is consistent with existing figures; the lifelong prevalence for mental health diseases in PC patients is estimated to be $42.7 \%$, and the one year prevalence for the general Portuguese population is $22.6 \%$ (DGS, 2013).

Mental health concerns were higher in women, older people and people with physical and functional problems as expected but when the model was adjusted, gender was no longer significant suggesting that older age, disease and functional impairment are more relevant than gender itself.

In this study patients with mental health problems had high levels of comorbidity with $78 \%$ scored for physical and medical concerns using the RISC. ADL were also associated with mental health problems with $45.4 \%$ of the patients having functional impairment. This was found to increase perceived risk, as judged by healthcare professionals, of all three adverse healthcare outcomes of interest in this study: institutionalization, hospitalization, and death.

We found that the best predictors of mental health problems were older age, impairment in ADL and medical problems, stressing the relevance of functionality and also comorbidity in old age corroborating other studies (Paul et al., 2006; Lee and Lee, 2011; Veerbeek et al., 2014). Loss of independence in performing ADL is a major concern for older people impacting 
upon self-perceived quality of life (Fernandez-Ballesteros et al., 2010). The relevance of caregiver networks to patients with mental health problems is established in the literature (Carretero et al., 2009) supporting other studies that suggest that competent caregiving can prevent risk of adverse outcomes (Giles et al., 2004). This study shows that almost half (48.5\%) of caregiver networks were perceived by healthcare professionals in PC to be able to manage mental health concerns; however, a further $32.9 \%$ were deemed under strain and 5\% unable to manage. The strain or burden placed on caregivers significantly increased the probability of perceived adverse outcomes, particularly for risk of institutionalization.

By comparing models we verified that the risk of institutionalization was increased when the caregiver network was deemed unable to cope. This again corroborates several studies stressing the importance of caregiver burden and its clear deleterious effects on older people including quality of life and increasing the cost of health and social care provision (Schulz and Martire, 2004).

This study has a number of limitations. The design was not able to examine point prevalence, but only the frequency or prevalence of cases in the selected study population. Thus, the sample is not probabilistic given that it was dependent on the willingness of the existing $\mathrm{PC}$ teams in the region to participate, introducing possible selection bias. This bias, however, does not affect the population selected, as most patients do not choose a GP but are assigned to one who is available. Further, this population-based study covers the whole northern region of Portugal increasing the external validity of the results. This cross-sectional study does not allow us to draw conclusions on a causal relationship between variables. Mental health, physical health and function are highly related such that mental disorders can be precursors of other chronic disease as well as the consequence of them (WHO and the Calouste Gulbenkian Foundation, 2014). The interaction between these conditions must be considered in screening and treatment strategies. Finally, this study presents the results of perceived rather than the actual risk of adverse outcomes, as scored by the RISC. Given the paucity of valid and reliable risk-prediction instruments available for use in the community (O'Caoimh et al., 2015a), the RISC seems a reasonable choice. Similar to the initial validation study in Ireland (O'Caoimh et al., 2012, 2015c) a prospective study is now underway in Portugal to determine whether the health care professionals predictions, as scored by the RISC, were able to accurately predict each of the three adverse outcomes of interest (institutionalization, hospitalization, and death) in Portugal. One-year outcomes are expected soon and further

\section{REFERENCES}

Bower, P., and Gilbody, S. (2005). Managing common mental health disorders in primary care: conceptual models and evidence base. BMJ 330, 839-842. doi: 10.1136/bmj.330.7495.839

Caldas de Almeida, J. M., and Xavier, M. (2013). Estudo Epidemiológico Nacional de Saúde Mental - 1 Relatório. Lisboa: Faculdade Ciências Médicas. studies will investigate the predictive validity of the RISC against other risk-prediction instruments. The RISC is also being investigated in other populations and countries including Spain and Australia.

\section{CONCLUSION}

Awareness of the importance of screening and assessing mental health concerns in PC is increasing. The RISC is a short, subjective, global risk-prediction instrument that can be used to train healthcare professionals (GPs and nurses) to screen and triage older people at risk of adverse outcomes including those with mental health problems. This instrument, unlike many others, includes an assessment of the patients' caregiver networks in its risk assessment algorithm (O'Caoimh et al., 2015a). Scoring the RISC is quick, suggesting that it can easily be incorporated into routine clinical practice. This study reaffirms the high prevalence of mental health disorders in PC, especially those with mild or subclinical syndromes, and highlights important factors such as age, and the presence of physical comorbidities and functional impairment, and the outcomes that they are perceived to predict. Given the current demand for services and the prevailing shortage of resources, the need to triage patients will continue. Early identification of mental health concerns in older patients in PC should allow healthcare professionals initiate prompt, appropriate and directed treatment. Further research is now required to confirm these findings.

\section{AUTHOR CONTRIBUTIONS}

CP and LT developed the study aim and design. LT undertook the analyses. MA, SA, and MD conducted the fieldwork and contribute to the discussion. ROC and WM developed the measurement instrument and trained the researchers. CP coordinated writing of the paper. All authors contributed to the final version.

\section{ACKNOWLEDGMENTS}

This work is supported by National Funds through the General Health Directorate of the Portuguese Ministry of Health grant and the FCT - Fundação para a Ciência e a Tecnologia (Portuguese National Funding Agency for Science, Research and Technology) in the frameworks of the PEstOE/SAU/UI0688/2014 project.

Carretero, S., Garces, J., Rodenas, F., and Sanjose, V. (2009). The informal caregiver's burden of dependent people: theory and empirical review. Arch. Gerontol. Geriatr. 49, 74-79. doi: 10.1016/j.archger.2008.0 5.004

DGS (2013). Portugal Saúde Mental em Números - 2013, Programa Nacional Para a Saúde Mental. Lisboa: Direcção Geral de Saúde.

EC (2010). Mental Health. Brussels: European Comission. 
Fernandez-Ballesteros, R., Garcia, L. F., Abarca, D., Blanc, E., Efklides, A., Moraitou, D., et al. (2010). The concept of 'ageing well' in ten Latin American and European countries. Ageing Soc. 30:556. doi: 10.1017/S0144686X09008587

Gallo, J. J., Rabins, P. V., Lyketsos, C. G., Tien, A. Y., and Anthony, J. C. (1997). Depression without sadness: functional outcomes of nondysphoric depression in later life. J. Am. Geriatr. Soc. 45, 570-578. doi: 10.1111/j.15325415.1997.tb03089.x

Ganguli, M., Dodge, H. H., and Mulsant, B. H. (2002). Rates and predictors of mortality in an aging, rural, community-based cohort: the role of depression. Arch. Gen. Psychiatry 59, 1046-1052. doi: 10.1001/archpsyc.59.11.1046

Giles, L. C., Metcalf, P. A., Glonek, G. F. V., Luszcz, M. A., and Andrews, G. R. (2004). The effects of social networks on disability in older Australians. J. Aging Health 16, 517-538. doi: 10.1177/0898264304265778

Hanley, J. A., and McNeil, B. J. (1983). A method of comparing the areas under receiver operating characteristic curves derived from the same cases. Radiology 148, 839-843. doi: 10.1148/radiology.148.3.6878708

Helmchen, H., Baltes, M., Geiselmann, B., Kanowski, S., Linden, M., Reischies, F., et al. (1999). "Psychiatric illness in old age," in The Berlin Aging Study, Aging From 70 to 100, eds P. Baltes and K. Mayer (Cambridge: Cambridge University Press), 167-196.

INE (2009). Inquérito Nacional de Saúde 2005/2006. Lisboa: INE, I.P.

Jeste, D., Alexoupoulos, G., Bartels, S., Cummings, J., Gallo, J., Gottlieb, G., et al. (1998). "Depression and depressive symptoms in old age," in Clinical Geropsychology, eds I. Nordhus, G. VandenBos, S. Berg, and P. Fromholt (Washington, DC: APA), 211-217.

Leahy-Warren, P., O'Caoimh, R., Fitzgerald, C., Cochrane, A., Svendrovski, A., Cronin, U., et al. (2015). Components of the risk instrument for screening in the community (RISC) that predict public health nurse perception of risk. J. Frailty Aging 4, 149-154.

Lee, E.-K. O., and Lee, J. (2011). Gender differences in predictors of mental health among older adults in South Korea. Int. J. Aging Hum. Dev. 72, 207-223. doi: 10.2190/AG.72.3.c

Lopes, A. (2013). "New approaches to familism in the management of social policy for old age in Portugal," in Aging in the Mediterranean, eds J. Troisi and H.-J. Kondratowitz (Bristol: Policy Press), 215-234.

Menchetti, M., Fava, C., and Berardi, D. (2001). Disability associated with depressive symptoms in elderly primary care attenders. Arch. Gerontol. Geriatr. Suppl. 7, 261-266. doi: 10.1016/S0167-4943(01)00147-9

O'Caoimh, R., Cornally, N., Weathers, E., O'Sullivan, R., Fitzgerald, C., Orfila, F., et al. (2015a). Risk prediction in the community: a systematic review of casefinding instruments that predict adverse healthcare outcomes in communitydwelling older adults. Maturitas 82, 3-21. doi: 10.1016/j.maturitas.2015.03.009

O'Caoimh, R., FitzGerald, C., Cronin, U., Svendrovski, A., Gao, Y., Healy, E., et al. (2015b). Which part of a short, global risk assessment, the Risk Instrument for Screening in the Community (RISC), predicts adverse healthcare outcomes? J. Aging Res. 2015, 256414.

O'Caoimh, R., Gao, Y., Svendrovski, A., Healy, E., O’Connell, E., O’Keeffe, G., et al. (2015c). The risk instrument for screening in the community (risc): a new instrument for predicting risk of adverse outcomes in community dwelling older adults. BMC Geriatr. 15:92. doi: 10.1186/s12877-015-0095-Z

O'Caoimh, R., Sweeney, C., Hynes, H., et al. (2015d). COLLaboration on AGEingCOLLAGE: ireland's three star reference site for the European Innovation Partnership on Active and Healthy Ageing (EIP on AHA). Euro. Geriatr. Med. 6, 505-511.

O'Caoimh, R., Gao, Y., Svendrovski, A., Healy, E., O'Connell, E., O'Keeffe, G., et al. (2014). Screening for markers of frailty and perceived risk of adverse outcomes using the risk instrument for screening in the community (RISC). BMC Geriatr. 14:104. doi: 10.1186/1471-2318-14-104

O'Caoimh, R., Healy, E., Connell, E. O., Gao, Y., and Molloy, D. W. (2012). The community assessment of risk tool, (cart): investigation of inter-rater reliability for a new instrument measuring risk of adverse outcomes in community dwelling older adults. Irish J. Med. Sci. 181:S227.
OECD (2013). Health at a Glance: OECD Indicators. Paris: OECD Publishing.

Paul, C., Ayis, S., and Ebrahim, S. (2006). Psychological distress, loneliness and disability in old age. Psychol. Health Med. 11, 221-232. doi: $10.1080 / 13548500500262945$

Paúl, C., and Martin, I. (2003). "Caregiver burden assessment," in Encyclopedia of Psychological Assessment. 1, ed. R. Fernández-Ballesteros (London: SAGE), 161-164.

Rabins, P. V., Black, B., German, P., Roca, R., McGuire, M., Brant, L., et al. (1996). The prevalence of psychiatric disorders in elderly residents of public housing. J. Gerontol. Biol. Sci. Med. Sci. 51, M319-M324. doi: 10.1093/gerona/51A.6.M319

Rockwood, K., Song, X., MacKnight, C., Bergman, H., Hogan, D. B., McDowell, I., et al. (2005). A global clinical measure of fitness and frailty in elderly people. Can. Med. Assoc. J. 173, 489-495. doi: 10.1503/cmaj.050051

Sarkisian, C. A., Lee-Henderson, M. H., and Mangione, C. M. (2003). Do depressed older adults who attribute depression to "old age" believe it is important to seek care? J. Gen. Int. Med. 18, 1001-1005. doi: 10.1111/j.1525-1497.2003.30215.x

Schulz, R., and Martire, L. M. (2004). Family caregiving of persons with dementia prevalence, health effects, and support strategies. Am. J. Geriatr. Psychiatry 12, 240-249. doi: 10.1097/00019442-200405000-00002

Steffens, D. C., Skoog, I., Norton, M. C., Hart, A. D., Tschanz, J. T., Plassman, B. L., et al. (2000). Prevalence of depression and its treatment in an elderly population - the cache county study. Arch. Gen. Psychiatry 57, 601-607. doi: 10.1001/archpsyc.57.6.601

Sweeney, C., Molloy, D. W., O’Caoimh, R., Bond, R., Hynes, H., McGlade, C., et al. (2013). European Innovation Partnership on Active and Healthy Ageing: Ireland and the COLLAGE experience. Ir. J. Med. Sci. 182, 278-279.

Veerbeek, M. A., Oude Voshaar, R. C., and Pot, A. M. (2014). Effectiveness and predictors of outcome in routine out-patient mental health care for older adults. Int. Psychogeriatr. 26, 1565-1574.

WHA (2012). The Global Burden of Mental Disorders AND The Need for a Comprehensive, Coordinated Response From Health and Social Sectors AT THE Country Level. World Healthy Assembly Resolution WHA 65.4. Geneva: World Health Organization.

WHO and the Calouste Gulbenkian Foundation (2014). Integrating the Response to Mental Health Disorders and Other Chronic Diseases in Health Care Systems. Geneva: WHO.

WHO and WFMH (2010). Mental Health and Chronic Physical Illnesses. The Need for Continued and Integrated Care. Woodbridge, VA: World Federation for Mental Health.

WHO and WONCA (2008). Integrating Mental Health into Primary Care: A Global Perspective. Geneva: World Health Organization.

Wittchen, H. U., Jacobi, F., Rehm, J., Gustavsson, A., Svensson, M., Jonsson, B., et al. (2011). The size and burden of mental disorders and other disorders of the brain in Europe 2010. Eur. Neuropsychopharmacol. 21, 655-679. doi: 10.1016/j.euroneuro.2011.07.018

Xavier, M., Baptista, H., Mendes, J. M., Magalhaes, P., and Caldas-de-Almeida, J. M. (2013). Implementing the world mental health survey initiative in portugal rationale, design and fieldwork procedures. Int. J. Ment Health Syst. 7:19. doi: $10.1186 / 1752-4458-7-19$

Conflict of Interest Statement: The authors declare that the research was conducted in the absence of any commercial or financial relationships that could be construed as a potential conflict of interest.

Copyright (c) 2015 Paúl, Teixeira, Azevedo, Alves, Duarte, O'Caoimh and Molloy. This is an open-access article distributed under the terms of the Creative Commons Attribution License (CC BY). The use, distribution or reproduction in other forums is permitted, provided the original author(s) or licensor are credited and that the original publication in this journal is cited, in accordance with accepted academic practice. No use, distribution or reproduction is permitted which does not comply with these terms. 